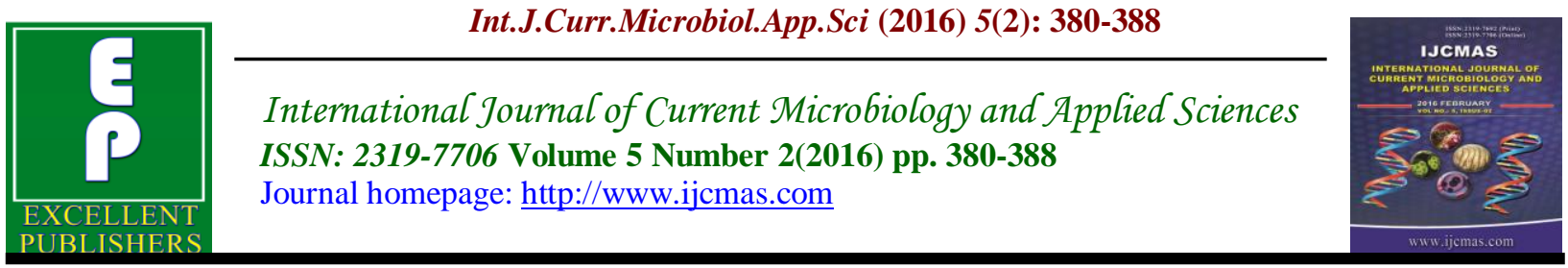

Original Research Article doi: http://dx.doi.org/10.20546/ijcmas.2016.502.043

\title{
Antimicrobial Assay and Minimum Inhibitory Concentration Values of Cistanche tubulosa
}

\section{Najeeb Ullah ${ }^{1}$, Abdur Rehman ${ }^{2}$, Sohail Ahmad ${ }^{4}$, Noreen Samad ${ }^{1}$, Hina Andaleeb1, Waqas Ahmad², Khadim Ahmad², Muhammad Haroon ${ }^{2}$, Shahid Maqbool', Adeela Altaf ${ }^{3}$ and Naima Raza $^{3}$}

${ }^{1}$ Department of Biochemistry, Bahauddin Zakariya University, Multan 60800, Punjab, Pakistan

${ }^{2}$ Department of Chemistry, Kohat University of Science and Technology,

Kohat, 26000, KPK, Pakistan

${ }^{3}$ Department of Environmental Sciences, Bahauddin Zakariya University, Multan 60800, Punjab, Pakistan

${ }^{4}$ Department of Chemistry, Qurtuba University of Science and Information Technology

Peshawar, Peshawar 25120, Pakistan

*Corresponding author

\begin{tabular}{|c|c|}
\hline & A B S T R A C T \\
\hline & The study describes the extraction, fractionation and antimicrobial activity of \\
\hline Keywords & $\begin{array}{l}\text { Cistanche tubulosa. The plant crude methanolic extract and all sub fractions } \\
\text { ( } n \text {-hexane, chloroform, ethyl acetate, n-butanol and aqueous) were subjected to }\end{array}$ \\
\hline & antibacterial and antifungal activity. Agar well diffusion method was used for \\
\hline & \\
\hline & diffusion. Hexane fraction show interesting results of abrupt change in inhibition \\
\hline & \\
\hline & oncentration. Same against $P$. \\
\hline & \\
\hline $\begin{array}{l}\text { Accepted: } \\
\text { 19 January } 2016 \\
\text { Available Online: } \\
\text { 10, February } 2016\end{array}$ & $\begin{array}{l}\text { antifungal activity methenaol, aqueous and hexane fractions show no inhibition at } \\
1 \mathrm{mg} / \mathrm{mL} \text { concentrataion against A.fumigatus. So the MIC values of these three } \\
\text { fractions is } 2 \mathrm{mg} / \mathrm{mL} \text { against A.fumigatus. Highest activity fraction was butanol } \\
\text { which gives wider zone of } 7 \mathrm{~mm} \text { against } A \text {. fumigantus. Whereas the same MIC } \\
\text { value of methanol extract is } 2 \mathrm{mg} / \mathrm{ml} \text { against A.niger. The results established a } \\
\text { good support for the use of } C \text {. tubulosa in traditional medicine. }\end{array}$ \\
\hline
\end{tabular}

\section{Introduction}

Bacteria and fungi cause dangerous human infections and are extremely pathogenic. As some strains of bacteria and fungi has the ability to become resistant due to production of various substances which inhibit the action of antibiotics or some time changing 
their target or stop their ability to penetrate the cells. Therefore these pathogenic microbes which have become resistant to antibiotic therapy are most common health problems. Tuberculosis, gonorrhea, malaria and childhood ear infection are some of the diseases which become hard to treat with antibiotic when these disease causing bacteria become resistant. A large part of problem is due to increasing use and misuse of existing antibiotic in human. As many of the modern and effective drugs which have their origin in traditional medicinal plant could also serve to substitute most of the synthetic antibiotics. Therefore medicinal plants have been used to treat humans. Herbal medicines have been practiced for thousands of centuries by tribes all over the world. From the earliest times until the end of nineteenth century plants are still the common source of medicinal treatment yet. Now days, the researchers are interested in medicinal plants and their chemistry because most of the plants have started widely used for food and therapeutic purposes (Rates, 2001; Vulto and Smet, 1988). The herbal medicine market has rapidly grown. Using natural, plant-derived medicines that are "healthier" than prescribed drugs derived from synthesized products is something that appeals to consumers (Ramsey et al., 2000). Cistanche tubulosa is the member of genus Cistanche. The genus Cistanche belongs to the family Orobanchacea. This genus is restricted to certain arid and semi arid regions of Africa, Asia and the Mediterranean. Cistanche with about 18 species is distributed in the arid and semi arid regions of the world (Agrwal et al., 1984; Blatter, 1921; Musselman, 1984). Cistanche is composed of holoparasite and perennial herbs, with alternative leaves and flowers arranged in spike or racemes. Its corolla is sub-actinomorphic and calyx lobes are rounded at the margin (Schneeweiss et al., 2004). Cistanche tubulosa is medicinaly very important. It is used as a blood circulation-promoting agent and in the treatment of impotence, sterility, lumbago, body weakness and tonic (Yoshikawa et al., 2006; Kobayashi et al., 1987). Cistanche tubulosa extract have been shown to be effective against various brain diseases, antiaging functions, metabolism of fat, and hair growth (Tanaka et al., 2008a; Tanaka et al., 2008b). Recently, several compounds including iridoids, monoterpenoids, phenylethanoid glycosides such as acteoside, echinacoside and cistanoside A, and lignans were isolated from C. tubulosa from China and Pakistan (Yoshikawa et al., 2006; Yoshizawa et al., 1990) and these phenylethanoid glycosides appear to have various biological activities, such as analgesic, anti-oxidant, and relaxation properties (Xiong et al., 2000; He et al., 2009). The effective chemical constituents of C.tubulosa extract are phenylethanoid glycosides, especially echinacoside and acteoside. C.tubulosa contains a higher amount of echinacoside than any other plant. Acteoside (a type of polyphenols) is 15times stronger anti-oxidative than resveratrol (polyphenols contained in grapes) and 5 times stronger than vitamin-C. Herba Cistanche, the dry stem of genus Cistanche (Orobanchaceae family) possess remarkable curative effects on kidney deficiency, neurasthenia and female infertility (Xie et al., 2006). By general experience, The picking time of C.tubulosa is traditionally before flowering, because pharmaceutical components in the stem is blot by flowering (Yang et al., 2005).

The aim of the study was to investigate the antibacterial and antifungal bioassays various extracts of C.tubulosa. The assessment of Minimum Inhibitory Concentration (MIC) was also the key focus of the study. 


\section{Materials and Methods}

\section{Collection and Drying of Plant Materials}

Sufficient quantity of Cistanche tubulosa plant was collected in April 2013 from KDA Karak Khyber Pukhtunkhwa, Pakistan in flowering season. The sample was washed properly with de-ionized water for removing dirt, dust and other possible parasites. The plant was dried at room temperature for nine days and then crushed into coarse powder using grinder and then stored in clean, dried plastic bags for further processing. The plant species was authenticated by the herbarium staff of Botany Department, Kohat University of Science and Technology and were kept in the laboratory for further process.

\section{Solvent Used in Experimental Works}

All the solvents used (i.e. chloroform, ethyl acetate, n-hexane and methanol) were filtered and also some amounts of dehydrated reagents $\left(\mathrm{MgSO}_{4}, \mathrm{Na}_{2} \mathrm{SO}_{4}\right)$ were added to purify the solvents before using.

\section{Extraction of Crude Extract}

The shad dried plant powder was chopped and soaked in methanol for 10 days. The solution was shaked 15 times a day to dissolve the plant material in methanol. The mixture obtained was filtered through clean cloth 3 times. The filtrate was evaporated under reduced pressure by using Vacuum Rotary Evaporator keeping the temperature at $50{ }^{\circ} \mathrm{C}$ to give crude extracts. Extracts was made dried and weighed.

\section{Fractionation of Crude Extract}

The crude extracts of Cistanche tubulosa was further suspended in water and partitioned successively with $n$-hexane, chloroform, ethyl acetate and $n$-butanol for obtaining $n$-hexane-soluble, chloroformsoluble, ethyl acetate-soluble, $n$-butanol soluble and aqueous soluble fractions, respectively. From each fraction the corresponding solvent was evaporated by rotary evaporator keeping specific temperature for each solvent. By this method, gummy residue of each friction was obtained.

\section{Preparation of Stock Solution}

Each fraction was dissolved in Dimethyl Sulfoxide (DMSO) of four different concentrations $4 \mathrm{mg} / \mathrm{ml}, 2 \mathrm{mg} / \mathrm{ml}, 1 \mathrm{mg} / \mathrm{ml}$ and $0.5 \mathrm{mg} / \mathrm{ml}$. Dimethyl Sulfoxide (DMSO) was used as solvent because it did not show any activity against bacteria. Therefore, in Dimethyl Sulfoxide (DMSO) most of the polar and non polar compound are soluble. That's why it was selected for antibacterial and antifungal activities. The crude extracts and subsequent solvents soluble fractions were then subjected to antimicrobial activity.

\section{Bacterial Strains}

Six bacterial strains Salmonella typhi, Staphylococcus aureus, Streptococcus pneumoniae, Klebsiella pneumonia, Proteus mirabilis and Escherichia coli, were used. These bacteria were cultured on nutrient broth (oxoid) at $37^{\circ} \mathrm{C}$ for 24 hours.

\section{Fungal Strains}

Three fungal strains were obtained from departmental culture stock which were originated from clinical cases. These fungi were Aspergillus fumigatus, Aspergillu niger and Aspergillus flavis. Each organism was cultured on sabouraud's dextrose agar medium incubated at $25^{\circ} \mathrm{C}$ for 7 days, for obtaining inoculums for testing. 


\section{Antimicrobial Assay}

In this study, various extracts of $C$. tubulosa were subjected for antimicrobial activities against Gram positive and Gram negative strain. The bacterial strains were tested by Agar Well Diffusion Susceptibility Method. All these microorganisms were obtained from the Department of Microbiology, KUST.

\section{Preparation of Media}

Media of nutrient agar was prepared in conical flask in accordance to the directions provided by the manufacturer. The media along with the Petri dishes, and pipette were sterilized in autoclave for 15 minutes at $121^{\circ} \mathrm{C}$ and 15 psi pressure. The media was then poured into Petri dishes under aseptic condition (Laminar flow hood) and let them for solidification for about 25 minutes.

\section{Methodology}

The antibacterial bioassay was done by Agar Well Diffusion Method, by measuring the zone of inhibition against the test microorganisms by using Najeeb Ullah et al. (2013) method. After solidification of media, wells of $6 \mathrm{~mm}$ were dug in media by using sterile plastic borer. Each well was given a specific number. Bacterial culture corresponding to $10^{4}$ to $10^{6}$ cfu (colony forming unit) was inoculated/streaked on the surface of the solidified media. Stock solutions of crude extracts and each fraction in DMSO at concentration of $4 \mathrm{mg} / \mathrm{ml}, 2$ $\mathrm{mg} / \mathrm{ml}, 1 \mathrm{mg} / \mathrm{ml}$ and $0.5 \mathrm{mg} / \mathrm{ml}$ were prepared and $1 \mathrm{~mL}$ from each stock solution was added into respective wells. The zones of inhibition were measured after 24 hours of incubation at $37^{\circ} \mathrm{C}$. Ciprofloxacin was used as standard and as a positive control while DMSO was used as a negative control. The zones of inhibition of crude extracts and fractions were compared with zones of inhibition of standard drugs ciprofloxacin. The amount of growth in each well was measured (Najeeb Ullah et al., 2013).

\section{Antifungal Bioassay}

The antifungal bioassay was determined by Agar Well Diffusion Method, following Atta-ur-Rehman et al (2001) method with some modifications and further results were verified by agar well diffusion method using Najeeb Ullah et al (2013) method.

\section{Methodology}

Three fungal strains were used for antifungal activities. Nutrient broth solution of concentration $13 \mathrm{~g} / \mathrm{L}$ in distilled water was used to refresh the fungal strains. Four flasks of $250 \mathrm{ml}$ were filled with broth and sterilized in autoclave. The fungal colonies were inoculated to each flask separately. The flasks were placed in incubator at $30^{\circ} \mathrm{C}$ for 3 days for refreshing fungal strains. In $500 \mathrm{ml}$ conical flask 14 grams of nutrient agar was taken and dissolved in $500 \mathrm{ml}$ of distilled water. The flask was autoclaved at $121^{\circ} \mathrm{C}$ for 15 minutes at 1.5 pounds pressure. About $9 \mathrm{ml}$ of medium was added to clean, dry and sterilized test tubes. One $\mathrm{ml}$ of sample was added to each test tube, the test tube was kept in inclined position to make a slant. The same process was repeated for all of test tubes. After solidifying, the fungi inoculums suspension was spread over the agar medium uniformly using sterile cotton swabs. After that the test tubes were kept in incubator for 3 days at $30^{\circ} \mathrm{C}$. After 3 days the fungal growth was observed in each test tube. We verify our results by agar well diffusion method and use petri dishes for this purpose and repeat the method as mentioned above in antimicrobial activity. 


\section{Results and Discussion}

\section{Antibacterial Activity (4mg/ml)}

In this study, the detailed spectrum of antibacterial activity of extract and various fractions of C.tubulosa was determined. The zones of inhibition formed by the fractions and crude are given in table-1. All fractions were active against six bacterial strains. No fraction was completely inactive. The crude extract was active against all bacterial species but showed more antibacterial activity against P.mirabilis, S.typhi, and E.coli while it showed less activity against S.Aureus. Aqueous fraction was highly active against S.typhi, but less active against E.coli, S.aureus. The ethyl acetate fraction showed good activity against S.Aureus, $S$. pneumoniae, P.mirabilis, while it showed less resistance against E.coli. The chloroform fraction was very active against S. aureus, S.pneumoniae while it show less activity against P.mirabilis. The $n$-hexane fraction give wider zone of inhibition against S.pneumoniae but it exhibited less activity against K.pneumoniae. Butanol fraction shows high activity against S.aureus, and E.coli but less activity against S.typhi.

\section{Results at $2 \mathrm{mg} / \mathrm{ml}$}

All fraction shows good activity still at $2 \mathrm{mg} / \mathrm{ml}$ but some fraction were inactive against some species at $1 \mathrm{mg} / \mathrm{ml}$. The MIC value of $2 \mathrm{mg} / \mathrm{ml}$ was observed for chloroform, ethyl-acetate and methanol fractions (Table 2). Ethyl-acetate and Chloroform at $2 \mathrm{mg} / \mathrm{ml}$ give the MIC value for P. mirabilis, E.coli while methanol fraction also gives MIC value for Escherichia coli at $2 \mathrm{mg} / \mathrm{ml}$.

\section{Results at $1 \mathrm{mg} / \mathrm{ml}$}

All fractions of C.tubulosa were also checked at $1 \mathrm{mg} / \mathrm{ml}$. The $\mathrm{n}$-Butanol fraction still showed high activity against S.typhi giving wider zone of inhibition of $5.5 \mathrm{~mm}$. This fraction also showed good activity against other bacterial strains. The value of zone of inhibition for different fraction against different bacterial strains has been recorded in table-3 given below.

The Fractions showing zero inhibition in $1 \mathrm{mg} / \mathrm{ml}$ concentration, they have the MIC values given in Table-2. Those fractions that did not show zero inhibition at $1 \mathrm{mg} / \mathrm{ml}$ concentration have MIC values given in Table- 3 because inhibition was checked at $0.5 \mathrm{mg} / \mathrm{ml}$ concentration. At this concentration the extract and fractions show no inhibition. Same procedure was performed for antifungal inhibition study at $0.5 \mathrm{mg} / \mathrm{ml}$ concentration.

\section{Antifungal Activity}

\section{Results at $4 \mathrm{mg} / \mathrm{ml}$}

All fractions showed activity against fungal species. Crude methanol extract and butanol fraction showed promising activities. Highest activity was shown by butanol fraction against $A$. fumagantus giving wider zone of $7 \mathrm{~mm}$. Methanolic extract against $A$. niger was least active giving lowest value of $2.5 \mathrm{~mm}$ (Table 4).

\section{Results at $2 \mathrm{mg} / \mathrm{ml}$}

The antifungal activities of different fraction of $C$. tubulosa were also carried out at $2 \mathrm{mg} / \mathrm{ml}$ to find out the MIC value against each fungal strain (Table 5). It has been found that that crude methanolic extract at $2 \mathrm{mg} / \mathrm{ml}$ gives MIC value for A.niger; A.fumigatus. Aqueous fraction gives MIC at $2 \mathrm{mg} / \mathrm{ml}$ for A.fumigatus. The $n$-hexane fraction at $2 \mathrm{mg} / \mathrm{ml}$ showed MIC value against A.fumigatus. The butanol fraction shows high activity at $2 \mathrm{mg} / \mathrm{ml}$ against A.fumigatus giving a wider zone of $6 \mathrm{~mm}$. 


\section{Results at $1 \mathrm{mg} / \mathrm{ml}$}

The different fractions of C.tubulosa were also tested against three fungal strains at $1 \mathrm{mg} / \mathrm{ml}$ (Table 6). It has been observed that butanol fraction at concentration of $1 \mathrm{mg} / \mathrm{ml}$ showed high activity against A.flavis with zone of inhibition of $4.1 \mathrm{~mm}$. The $n$-hexane fraction was also highly active against A.flavis giving zone of inhibition of $2.5 \mathrm{~mm}$.

Natural alternative treatments for fungal and bacterial infections may provide a pathway for the development of new antimicrobial agents. Our study indicated that all the six fractions (aqueous, methanol, hexane, butanol, chloroform and ethyl-acetate) of Cistanche tubulosa were more potent against the selected Gram-positive and Gram-negative bacteria and seleceted fungi. Our study emphasizes that the medicinal plant $C$. tubulosa is active against hospital strains of, S.aurous, S.pyogenes, E.coli, S.typhi, P.mirabilis, and K.pneumonea and fungal strains. However, this finding was consistent on repeated experiments and warrants further investigation. Inhibition zone sizes that were obtained supported the findings of the well diffusion method. Further studies will determine what compounds are active in the various extracts. However; extracts of C.tubulosa may be a good target for investigations since it contains compounds with bioactivity. The bioactive compounds may not be limited to those already identified.

Table.1 Antibacterial Activity of Extract and Fractions of Cistanche tubulosa at $4 \mathrm{mg} / \mathrm{ml}$ against Bacteria Strains

\begin{tabular}{|l|l|l|l|l|l|l|l|}
\hline \multirow{2}{*}{$\begin{array}{c}\text { Bacterial } \\
\text { strains }\end{array}$} & Methanol & Aqueous & $\begin{array}{c}\text { Ethyl- } \\
\text { acetate }\end{array}$ & Chloroform & n-Hexane & Butanol & $\begin{array}{l}\text { Standard Drug } \\
\text { Ciprofloxacin } \\
(30 \mu \mathrm{g})\end{array}$ \\
\hline S.typhi & 6.0 & 7.1 & 6.6 & 4.6 & 4.5 & 6.0 & 10.1 \\
\hline S.aureus & 4.0 & 4.1 & 7.1 & 5.0 & 4.9 & 7.2 & 9.9 \\
\hline S.pneumoniae & 5.9 & 5.0 & 7.3 & 5.4 & 7.0 & 6.1 & 10.4 \\
\hline K.pneumonia & 5.0 & 4.0 & 5.8 & 5.0 & 3.5 & 7.0 & 11 \\
\hline P.mirabilis & 8.0 & 6.0 & 7.0 & 4.2 & 5.5 & 6.8 & 10.5 \\
\hline E.coli & 6.0 & 4.0 & 5.5 & 4.5 & 5.0 & 7.0 & 11.2 \\
\hline
\end{tabular}

Table.2 Antibacterial Activity of Extract and Fraction of Cistanche tubulosa at Concentration of $2 \mathrm{mg} / \mathrm{ml}$

\begin{tabular}{|c|c|c|c|c|c|c|c|}
\hline \multirow[b]{2}{*}{$\begin{array}{l}\text { Bacteria } \\
\text { strains }\end{array}$} & \multicolumn{7}{|c|}{ Zone of inhibition (mm) } \\
\hline & Methanol & Aqueous & $\begin{array}{l}\text { Ethyl- } \\
\text { acetate }\end{array}$ & Chloroform & $\begin{array}{c}\text { n- } \\
\text { Hexane }\end{array}$ & Butanol & $\begin{array}{l}\text { Standard Drug } \\
\text { Ciprofloxacin: } 30 \mu \mathrm{g}\end{array}$ \\
\hline S.typhi & 4.5 & 6.8 & 6 & 4 & 3 & 5.5 & 10.1 \\
\hline S.aureus & 3.5 & 3.5 & 4.5 & $4.0 \mathrm{MIC}$ & 4.0 & 6 & 9.9 \\
\hline S.pneumoniae & 5.0 & 2.3 & $3.1 \mathrm{MIC}$ & 3.2 & 1.5 & 5.2 & 10.4 \\
\hline K.pneumoniae & 4.5 & 3.3 & 4.8 & 2.0 & 3.0 & 4.7 & 11 \\
\hline P.mirabilis & 5.0 & 4.1 & $5.0 \mathrm{MIC}$ & $3.0 \mathrm{MIC}$ & 3.1 & 6.0 & 10.5 \\
\hline E.coli & $4.1 \mathrm{MIC}$ & 3.0 & $3.1 \mathrm{MIC}$ & $4.0 \mathrm{MIC}$ & 4.1 & 6.5 & 11.2 \\
\hline
\end{tabular}


Table.3 Antibacterial Activity of Extract and Fraction of Cistanche tubulosa at Concentration of $1 \mathrm{mg} / \mathrm{ml}$

\begin{tabular}{|c|c|c|c|c|c|c|c|}
\hline \multirow[b]{2}{*}{$\begin{array}{l}\text { Bacterial } \\
\text { strains }\end{array}$} & \multicolumn{7}{|c|}{ Zone of inhibition (mm) } \\
\hline & Methanol & Aqueous & $\begin{array}{l}\text { Ethyl- } \\
\text { acetate }\end{array}$ & Chloroform & $\begin{array}{c}\text { n- } \\
\text { Hexane }\end{array}$ & Butanol & $\begin{array}{l}\text { Standard Drug } \\
\text { Ciprofloxacin } \\
(30 \mu \mathrm{g})\end{array}$ \\
\hline S.typhi & 4 & 5.8 & 5 & 3.2 & 1.5 & 5.5 & 10.1 \\
\hline S.aureus & 3.0 & 1.0 & 4.0 & 0.0 & 1.8 & 5.0 & 9.9 \\
\hline S.pneumoniae & 3.0 & 1.0 & 0.0 & 2.7 & 1.0 & 4.1 & 10.4 \\
\hline K.pneumoniae & 3.8 & 3.0 & 3.2 & 4.2 & 2.8 & 4.5 & 11 \\
\hline P.mirabilis & 3.5 & 3.5 & 0.0 & 0.0 & 4.0 & 5.4 & 10.5 \\
\hline E.coli & 0.0 & 1.0 & 0.0 & 0.0 & 3.2 & 5.0 & 11.2 \\
\hline
\end{tabular}

Table.4 Antifungal Activities of Six Fractions of Cistanche tubulosa at 4mg/ml

\begin{tabular}{|l|c|c|c|c|c|c|}
\hline & \multicolumn{7}{|c|}{ Zone of inhibition (mm) } \\
\cline { 2 - 7 } Fungal strains & Methanol & Aqueous & Ethyl-acetate & Chloroform & n-Hexane & Butanol \\
\hline A. nigar & 2.5 & 5.1 & 4.0 & 3.5 & 5 & 6.7 \\
\hline A. fumigatus & 4.2 & 4.0 & 5.0 & 5.1 & 3 & 7 \\
\hline A. flavis & 6.0 & 4.2 & 6.1 & 4.0 & 5.3 & 6.2 \\
\hline
\end{tabular}

Table.5 Antifungal Activities of Crude Extract and Fractions of Cistanche tubulosa at 2mg/ml

\begin{tabular}{|l|c|c|c|c|c|c|}
\hline \multirow{2}{*}{$\begin{array}{l}\text { Microorganism } \\
\text { (Fungal strains) }\end{array}$} & \multicolumn{6}{|l|}{ Zone of inhibition (mm) } \\
\cline { 2 - 8 } & Methanol & Aqueous & Ethyl-acetate & Chloroform & n-Hexane & Butanol \\
\hline A. niger & $2.1 \mathrm{MIC}$ & 3.1 & 3.2 & 3.0 & 2.5 & 3.7 \\
\hline A.fumigatus & $3.5 \mathrm{MIC}$ & $1.0 \mathrm{MIC}$ & 3.9 & 3.7 & $2.6 \mathrm{MIC}$ & 6.0 \\
\hline A. flavis & 4.0 & 3.3 & 5.5 & 3.0 & 3.2 & 5.5 \\
\hline
\end{tabular}

Table.6 Antifungal Activities of Crude Extract and Fractions of Cistanche tubulosa at 1mg/ml

\begin{tabular}{|l|c|c|c|c|c|c|}
\hline \multirow{2}{*}{$\begin{array}{l}\text { Microorganism } \\
\text { (Fungal strains) }\end{array}$} & \multicolumn{7}{|c|}{ Zone of inhibition (mm) } \\
\cline { 2 - 7 } & Methanol & Aqueous & Ethyl-acetate & Chloroform & n-Hexane & Butanol \\
\hline A. nigar & 0.0 & $1.5 \mathrm{MIC}$ & 2.4 & $1.4 \mathrm{MIC}$ & 1.2 & $1.0 \mathrm{MIC}$ \\
\hline A. fumigatus & 0.0 & 0.0 & $2.3 \mathrm{MIC}$ & $2.0 \mathrm{MIC}$ & 0.0 & 3.0 \\
\hline A. flavis & $2.1 \mathrm{MIC}$ & 3.0 & 3.2 & $1.2 \mathrm{MIC}$ & 2.5 & 4.1 \\
\hline
\end{tabular}

In conclusion, based on the pharmacological results of the present study, it could be said concluded the plant extracts contain chemical constituents of pharmacological significance. The presence of these chemical constituents in this plant is an indication that, if this plant is properly screened by using additional solvents, it could yield drugs of pharmaceutical significance. Further research is therefore recommended to isolate, purify and characterize chemical constituents with a view to supplementing conventional drug development especially in developing countries. The results of our 
present study suggest that each fraction of C.tubulosa possess different effect in antibacterial bioassay. It is recommended that C.tubulosa is an important plant from medicinal point of view. In future it would lead to the formulation of safe herbal medicine of global interests with least side effect. It could be concluded that Cistanche tubulosa has potentially higher antifungal efficacy. All tested extracts have lesser antifungal efficacy than standard against microbes examined. Different antifungal activity of plant extracts might be due to present of different active phytocompounds. Further study is required to determine the different antifungal compounds from C.tubulosa and their full spectrum. This medicinal plant open the prospect of finding new clinically efficient antifungal compounds and the knowledge about the botanical preparation of traditional sources of medicinal plants can be extended for future investigation into the field of pharmacology, phytochemistry or food chemistry for drug discovery.

\section{References}

Agrawal, K.C., Parker, C., Musselman, L.J., Polhill, R.M. and Wilson, A.K. (1984): Ecological studies of Cistanche tubulosa" Wight. In: C. Parker, L.J. Musselman, Polhill.R.M. And Wilson.A.K.(eds.). Proceedings of the 3rd International Symposium of Parasitic Weeds.-Aleppo, Syria. 31-39.

Ali, R., Farid, F., Hussain, U., Saima, S., Sohail, A., Najeeb, U. and Nasir, M. (2013): Antibacterial Study of Medicinal Plant Trigonella foenum", IJBMSP., 3(1): 17-18.

Blatter, E. (1921). Flora Arabia III. Records of the Botanical Survey of India, 8(3): 351.

He.W.J., Fang, T.H., Ma, X., Zhang, K., Ma,
Z.Z. and Tu, P.F. (2009): Echinacoside elicits endothelium-dependent relaxation in rat aortic rings via an NO-cGMP pathway. Planta Med., 75: 1400-1404.

Kobayashi, H., Oguchi, H., Takizawa, N., Miyase, T., Ueno, A., Usmanghani, K. and Ahmad, M. (1987): NewPhenylethanoid Glycosides from Cistanche tubulosa (SCHRENK) HOOK. Chem Pharm Bull., 35: 33093314.

Musselman, L.J. (1984): Some Parasitic Angiosperms of Sudan. Hydronaceae, Orobanchaceae and Cuscuta (Convolvulaceae). -Notes RBG Edinb. 42(1): 21-38.

Najeeb.U., Saima, S., Ali, R., Hussain, U., Farhan and Ijaz. A. (2013): Antibacterial and antifungal study of Spergula arvensis. Int $\mathbf{J}$ Sci Inn Discov., 3(3): 348-352.

Ramsey, L.A., Ross, B.S. and Fischer, R.G. (2000): Efficacy, Safety, reliability, common concerns about herbal products. herb.Sci., 31.

Rates, S.M. (2001): Plants as source of drugs. Toxicon., 39: 603.

Rehman, A., Chaudhry, M.I. and Thomson, W.J. (2001): Bioassay Techniques for Drug Development, Harwood Academic, Amsterdam., 9: 24.

Schneeweiss, G.M., Palomeque T. and Colwell. (2004): Chromosome numbers and karyotype evolution in holoparasitic Orobanche (Orobanchaceae) and related genera. American J Bot., 91: 348-349.

Tanaka, J., Su M.H. and Shimoda, H. ( 2008a): Effect of Cistanche tubulosa extract on various brain diseases. Food Sty., 21(12): 24-26.

Tanaka, J., Shan, S.J., Su, M.H. and Shimoda, H. (2008b): Fat metabolizing effect of Cistanche tubulosa extract. Food Sty., 21(12): 30-33. 
Vulto, A.G. and Smet, P.A.G.M. (1988): Drugs used in non-orthodox medicine. In: Meyer's Side Effect of Drugs, Dukes, M. M. G. (ed.), 11th ed, Elsevier, Amsterdam.

Xie, H.H., Morikawa, T., Matsuda, H., Nakamura, S., Muraoka, O. and Yoshikawa, M. (2006): Monoterpene constituent from Cistanche tubulosachemical structures of kankanosides A-E and kankanol. Chem Pharm Bull., 54(5): 669-675.

Xiong, Q., Tezuka, Y., Kaneko, T., Li, H., Tran, L.Q., Hase, K., Namba, T. and Kadota, S. (2000): Inhibition of nitric oxide by phenylethanoids in activated macrophages. Euro J Clin Pharm., 14: $137-144$.
Yang. J.H., Du N.S. and Kasim. R. (2005). J Chinese Pharm Sci., 14: 242.

Yoshikawa, M., Matsuda, H., Morikawa, T., Xie, H., Nakamura S. and Muraoka, O. (2006):Phenylethanoid oligoglycosides and acylated oligosugars with vasorelaxant activity from Cistanche tubulosa. Bioorg Med Chem., 14: 746747.

Yoshizawa, F., Deyama, T., Takizawa, N., Usmanghani, K. and Ahmad, M. (1990). The constituents of Cistanche tubulosa Schrenk (Hook) f. I. I., Isolation and structure of a new phenylethanoid glycoside and a new neolignan glycoside. Chem Pharm Bull., 38: 1927-1930.

\section{How to cite this article:}

Najeeb Ullah, Abdur Rehman, Sohail Ahmad, Noreen Samad, Hina Andaleeb, Waqas Ahmad, Khadim Ahmad, Muhammad Haroon, Shahid Maqbool, Adeela Altaf and Naima Raza. 2016. Antimicrobial Assay and Minimum Inhibitory Concentration Values of Cistanche tubulosa. Int.J.Curr.Microbiol.App.Sci. 5(2): 380-388. doi: http://dx.doi.org/10.20546/ijcmas.2016.502.043 